Available online at www.jmle.org

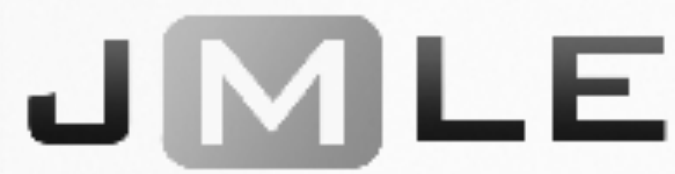

The National Association for Media Literacy Education's

Journal of Media Literacy Education 9 (2), 45 - 57

\title{
Social Media Literacy as an IEP Intervention for Social and Emotional Learning
}

\author{
Donnell Probst \\ San Jose State University
}

\begin{abstract}
Media literacy and special education communities have largely ignored the impact of digital media use on special education students with Autism spectrum disorder and Emotional and Behavioral Disorder. This paper investigates the possibility of using social media literacy education as part of an individualized education plan (IEP) intervention for improving the social and emotional learning outcomes of students with disabilities. Using the example of a "provocative selfie" as a form of media production and consumption, this paper provides a framework for using the NAMLE key questions to teach specific CASEL Social and Emotional (SEL) competencies and address IEP goals and objectives of students with social and emotional deficits. By using the key questions of media literacy to teach the CASEL competencies, educators can provide special education students with strategies for analyzing, evaluating, creating, and acting responsibly in the digital world while remediating poor social and emotional skills commonly associated with many social, emotional, and behavioral disorders.
\end{abstract}

Keywords: media literacy, social media literacy, special education, autism spectrum disorders, emotional behavioral disorders, IEP

Social and emotional learning (SEL) in the education environment is widely accepted as an important aspect of a Fair and Appropriate Education (FAPE) under the Individuals with Disabilities Education Act (Howey, 2012). But what does social and emotional learning look like for the 21 st century (21C) student with disabilities? While social skills training has been a staple of individualized education plans (IEP) for students with autism spectrum disorders and emotional behavioral disorders (EBD) who have deficits in social and emotional learning, conventional interventions have failed to address the way in which modern 
students with disabilities communicate, create, and share information. The purpose of this paper is to identify parallels in social skills deficits in offline and online interactions for students with disabilities and determine how special educators can align the National Association for Media Literacy Education's (NAMLE) Key Questions to the Collaborative for Academic, Social, and Emotional Learning (CASEL)'s five core competencies to build a social media literacy education framework which will serve to improve the social and emotional learning outcomes of students with autism spectrum disorders and emotional and behavioral disorder.

When such students pick up a mobile device or log onto a computer, there are a number of social, emotional and behavioral issues they may experience as a result of their disability, including issues with focus and attention, impulse control, depression and anxiety, self-esteem, bullying, sexuality and body image, and more. Researchers have identified an almost identical list of issues in neurotypical students resulting from the extensive use of a variety of media (Boyle et al., 2016; den Hamer \& Konijn, 2015; Fardouly \& Vartanian, 2016; Lim \& Yang, 2015; Woods \& Scott, 2016). These findings stimulate interest in exploring how students with autism spectrum disorders and emotional and behavioral disorder may be predisposed to the negative effects of social media use. Such evidence raises questions about whether or not these effects may compound existing deficits in students with disabilities. There is minimal literature studying the effects of social media on the social and emotional learning of adolescents with specific learning, behavior, and developmental disabilities, and consequently an absence of social skills training programs for students with disabilities adapted to $21 \mathrm{C}$ literacies, such as media literacy.

\section{Social Emotional Learning}

Social and emotional learning is a staple in special education due to an existing correlation between academic achievement and social and emotional competencies as they affect the educational setting (Brackett \& Rivers, 2013). Salovey and Mayer defined social intelligence as, "the ability to understand and manage people," and emotional intelligence as, "the ability to monitor one's own and others' feelings and emotions, to discriminate among them and to use this information to guide one's thinking and actions" (1990, p. 141). The existence of emotional intelligence is directly correlated to an individual's capability for problem solving and maintains that students must not only achieve academically, but they must also effectively navigate a variety of influences, relationships, and social situations in order to become productive, contributing members in their education (Elias et al., 1997).

Some of the most significant positive outcomes of a student possessing well-developed social and emotional skills are improved academic performance, motivation, and classroom behavior, while negative behaviors such as aggression, noncompliance, depression, anxiety, stress, and social withdrawal are reduced (CASEL(b), 2016). Conventional special education practices address social and emotional skills through Individualized Education Plans goals focused on face-toface peer interactions (Adams, 2013), but in the past decade the communication 
methods of all students have changed to reflect a changing media landscape. Researchers and special educators have failed to adapt to these changes, leaving students with disabilities without the tools necessary to participate effectively in a $21 \mathrm{C}$ society.

Emerging research indicates that social interactions among adolescents are moving online with $45 \%$ of teens now using social media every day, and $10 \%$ of those individuals spending more than nine hours a day on various social networking websites (Common Sense Media, 2015; Kennedy \& Lynch, 2016). While there are many benefits to social media use, the documented negative effects of extensive media use on neurotypical adolescents reflects issues with off-task behaviors (Hollis \& Was, 2016), stress, anxiety, and depression (Woods \& Scott, 2016), empathy (Vossen \& Valkenburg, 2016), loneliness (Pittman \& Reich, 2016), and awareness of others (Hwang, 2015). While each of these issues are linked to poor academic performance in social and emotional learning research, Flanigan and Babchuk's (2015) research made a direct correlation to social media use and academic motivation. The extensive use among all adolescents, including those with disabilities, highlights the need for research and programming to address social and emotional learning skills, which provide students with disabilities the tools necessary to interact with their peers, on and offline.

\section{Media Literacy Education and Disabilities}

The growing recognition of the importance of media literacy education has resulted in an expanding body of research surrounding the impact of media use on neurotypical adolescents and teens, however, there is very limited research specific to students with disabilities. By comparing bodies of research on media use by adolescents without disabilities and the deficits of students with autism spectrum eisorders and emotional and behavioral disorder, we can begin to understand the potential compound effect of media use on individuals with disabilities.

Some evidence suggests the importance of examining how online interaction may fuel harmful social comparison. For example, in a 2006 study, Hedley and Yang outline how social comparison fuels depressive symptoms in children and adolescents with autism spectrum disorders. Similarly, Lim and Yang's (2015) research concludes that social media use causes envy and shame as a result of social comparison among neurotypical individuals, indicating that individuals with disabilities may be at increased risk for symptoms of depression, envy, and shame resulting from social media use (Howey, 2012). Significant research also exists regarding the comorbidity of autism spectrum disorders and attention deficit disorders (Leitner, 2014), which is compounded by findings from Odaci and Celik (2016) linking Internet dependence to poor social relations, impulse control, coping ability, and body image.

Cyberbullying is also a systemic problem linked to media users with low levels of media literacy (den Hamer \& Konijn 2015). Research indicates that students with disabilities are more likely to engage in behavior which precedes negative feedback from peers, including hypersexualization, poor social 
competence, and lack of restraint when pursuing new social relationships (Koutamanis, Vossen, \& Valkenburg 2015). As a result, these learners may be more likely to experience victimization on social media (Kowalski et al., 2016).

Outside of the negative effects of social media, there are benefits to the appropriate use of social media by adolescents. Valkenburg and Vossen's (2016) study indicates that social media use can improve "both their ability to understand (cognitive empathy) and share the feelings of their peers (affective empathy)" (p. 118). Empathy (both cognitive and affective) is often a deficit experienced by students with autism spectrum disorders (Baron-Cohen \& Wheelwright, 2004), providing further support for the exploration of new frameworks through which students with disabilities can address social and emotional learning skills through media literacy education.

\section{Existing Frameworks for SEL and MLE}

While there is a growing body of research in the areas of social emotional learning and media literacy education, researchers need to begin to look at how existing learning frameworks within these fields can be integrated to serve an interdisciplinary need. The National Association for Media Literacy Education (NAMLE) has an established framework of core concepts which assists educators in helping students to critically evaluate the media they consume, use all types of media responsibly, and is intended for use in creating clear and measurable outcomes for media literacy education for all students (NAMLE, 2007). As part of this framework, a list of "Key Questions to Ask When Analyzing Media Messages," (Rogow \& Scheibe, 2007) prompts help students analyze and evaluate individual media messages of all types. This framework is currently used extensively in pre-K through post-secondary classrooms around the world, but is largely absent from special education classrooms and individualized education plans for students with autism spectrum disorders and emotional and behavioral disorder who actively use, and often overuse, various forms of media ( $\mathrm{Li}$ et al., 2016).

A widely-accepted practice for teaching social and emotional learning skills for students of all ages and abilities is the Collaborative for Academic, Social, and Emotional Learning (CASEL) framework. It consists of five core competencies which are used to guide pedagogical practices in the classroom. These competencies include: self-awareness, self-management, social awareness, relationship skills, and responsible decision making (CASEL(a), 2016). For students with autism spectrum disorders and emotional and behavioral disorder, these competencies often provide the framework for creating specific, measurable, achievable, relevant, and time bound goals in the area of social and emotional skills in an individualized education plan. If the CASEL social and emotional learning competencies are compared to the outcomes described in the NAMLE Core Competencies for Media Literacy Education, we can begin to see a parallel of concepts and pedagogy which emphasizes similar outcomes for both media literacy education and social and emotional learning including empathy, impulse control, relationship-building, ethical responsibility, organizational skills, and issues with perception (CASEL(a), 2016). 
These competencies are commonly addressed for students with disabilities through in-person social skills training in an individualized education plan, and for neurotypical students through media literacy education, but these two frameworks have not previously been compared or combined to create a comprehensive media literacy framework for students with specific learning needs. By drawing on principles from both the NAMLE and CASEL frameworks, special educators may begin to create a new framework for addressing social and emotional learning deficits through social media literacy education.

By identifying social media literacy competencies and programs which align to existing social and emotional learning goals in a student's individualized education plans (IEP), social media literacy may effectively replace conventional in-person social skills interventions with social media literacy lessons. When this happens, students with autism spectrum disorders and emotional and behavioral disorder could receive social skills training which could provide them with modern tools and skills necessary to communicate effectively and safely with their peers on $21 \mathrm{C}$ platforms.

\section{Using CASEL and NAMLE as an IEP Intervention}

As shown in Table 1, there are several broad examples of how the CASEL and NAMLE competencies can be applied to social and emotional learning goals in an individualized education plan for students with autism spectrum disorders and emotional and behavioral disorder. The CASEL competency of social awareness, defined as, "the ability to take the perspective of and empathize with others... the ability to understand social and ethical norms for behavior" (CASEL(a), 2016, para. 2) can be supported through various digital citizenship curriculums which use the NAMLE key questions to ask students to evaluate media by asking questions of the students such as, "Who might be harmed by this message?" or "How might I participate productively?" (Rogow \& Scheibe, 2007).

The CASEL competency of Responsible Decision Making can be fulfilled in a variety of social media literacy programs including topics like digital citizenship, sexting, bullying, and privacy. This competency defined as, "The ability to make constructive choices about personal behavior and social interactions based on ethical standards, safety concerns, and social norms" (CASEL, 2016) can use a variety of NAMLE key questions as prompts for critical understanding of media production and consumption, such as, "Who might be harmed by this message," "What actions might I take in response to this message?" or "Is this message good for me?" (Rogow \& Scheibe, 2007).

Discussions about embedded messages in various media such as, "all media messages contain embedded values and points of view," (NAMLE, 2007), can help students with autism spectrum disorders and emotional and behavioral disorder understand the point of view of others and help students develop empathy, a key deficit for many of these students. 
Table 1

NAMLE Core Principles \& CASEL Competencies

\begin{tabular}{ll}
\hline CASEL Competencies & Media Literacy Key Questions \\
\hline Self-awareness & What does this want me to think (or think about)? \\
& How does this make me feel and how do my emotions \\
influence my interpretation of this? & What is my interpretation and what do I learn about \\
& myself from my reaction or interpretation? \\
Self-management & What actions might I take in response to this message? \\
Social awareness & Who is the target audience? Who are they talking to, or \\
& who is this for? \\
& Who might be harmed by this message? Who might \\
benefit? & What would someone learn from this? \\
What ideas, values, or points of view are represented? & How might different people understand this message \\
differently? & \\
What does the storyteller want me to remember? & Can I trust this source to tell me the truth about this \\
topic?
\end{tabular}

Note: Adapted from CASEL(a), 2016 and Rogow \& Scheibe, 2007

\section{Case Study: Provocative Selfies}

The following is a sample of how NAMLE's key questions were used as an intervention for social and emotional learning for a 16-year-old female student diagnosed with an autism spectrum disorder, ADHD and anxiety. The scope of this paper is limited, serving to identify and describe a current gap within the interdisciplinary field of media literacy and disabilities, identify the benefits of addressing this gap for the described

Sample IEP Goal: "Given examples of images shared on social media, <Student $>$ will demonstrate perspective taking by identifying more than three possible perspectives in response to NAMLE key questions about various images on social media without prompts $4 / 5$ times on 3 separate occasions." population, and to propose a potential model for further research and refinement.

Context. The data for this study was gathered in the homeschool setting, where the researcher, an emerging media literacy professional and special education advocate, is both the parent and educator of the participant, a role which informed the application of social media literacy principles to casual observations 
of the participant's behavior over the course of three years prior to the formal observation.

Method. This case study includes a sample social and emotional learning /social media literacy goal along with a framework for inquiry-based discussion prompts designed to elicit critical evaluation of an image from social media. This student has a history of presenting difficulty with perspective-taking but has experienced some success generalizing in-classroom social skills training to real life social interactions. This student's moderate success with conventional social skills programs made them an ideal candidate for this case study as we know this student has some ability to take the perspective of others with direct instruction in social and emotional learning.

For this case study, the student selected three images from Instagram to evaluate. The first image selected by the student was a teenage girl laying across a fallen tree in a two-piece swimsuit in the middle of an open field. The second and third image were from Instagram accounts the student identified as "famous" social media personalities. Both images 2 and 3 portrayed images of the female body up close wearing very little clothing. The student was asked a series of questions based on NAMLE's key questions, followed by an overview of the analysis of additional images by the student and outcomes for these subsequent interventions.

The following series of questions were asked regarding the first image selected by the student of the teenage girl laying across a fallen tree in a two-piece swimsuit in a field. Figure 1 displays the image which has been altered to protect the identity of the individual depicted in the image.

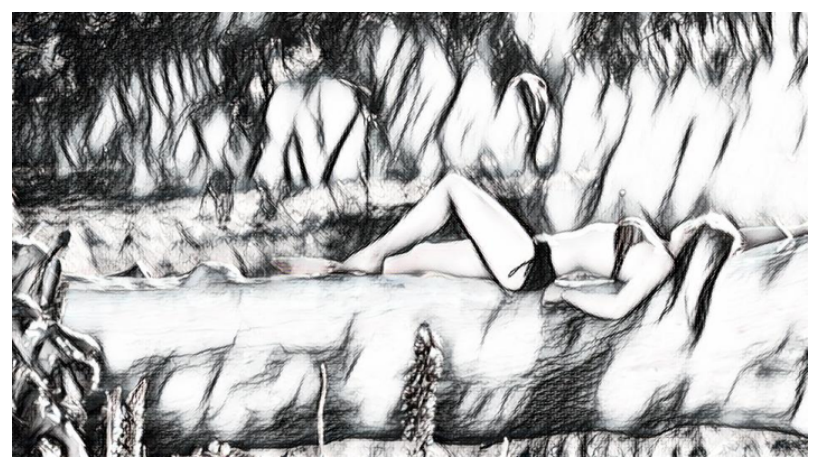

Figure 1.

Girl lying across fallen log in swimsuit. Illustration adapted from Instagram.

The researcher obtained qualitative data through a convergent interview process between the participant and the researcher. A list of prompts was prepared prior to the interview, which was delivered in a face-to-face setting. The researcher explained to the participant that a series of questions would be asked in order to better understand the participant's perception of images they view online. The participant was not provided additional information about the purpose of the interview in order to avoid changes in the participant behavior related to reactivity or compliance. The participant was then asked to select three images of people from her Instagram feed, which included accounts the participant follows and is 
therefore more likely to view on a regular basis. For each image, the researcher began with an initial question and then continued in a conversational tone, offering prompts to help address a variety of the areas covered by the NAMLE Key Questions or clarify the participant's responses. The participant provided verbal responses which were then recorded by the researcher.

\section{Findings}

Question 1: Who is the target audience? (Social Awareness)

The student responded with two obvious audiences including "Boys, but mostly girls." When the student received an additional prompt asking about other people who may be able to see the image the student identified parents and young children, noting that it would not be appropriate for those audiences. A third prompt was required to elicit responses about wider audiences, such as employers, colleges, and grandparents. Further discussions included whether this individual who had posted the image had considered all audiences, requiring the student to consider the other individuals perspective and motivations.

Question 2: What message are they trying to communicate with this image?

(Social Awareness)

The student responded to this prompt with the statement, "I have a nice body and I don't care if people see me like this." When asked why they think the person doesn't care if people see her like this, the student responded that the individual did not care about being decent and has low standards for herself. Further prompts included whether or not this image conveyed any positive messages such as strength or adventure and how this might impact the way people viewing this image might affect or limit their opinion of this person. The student responded that the image put a lot of emphasis on her looks, so people might not consider whether or not she is smart.

Question 3: How does this make me feel? (Self-awareness)

This question is designed to encourage students to investigate their own thoughts and feelings about an image they see and determine how their thoughts and feelings affect their perception of the person posting the image. The student initially responded that she felt envious and it made her compare her own body to the image, but then quickly added that she felt sorry for the girl that she felt she needed to share that image.

Question 4: What is my interpretation? (Self-awareness)

This question elicited a repetition of previous responses about the message the girl in the image was trying to communicate and required additional prompts to help the student critical evaluate their interpretation including, "Does it make me feel more or less desirable or attractive?" "Does this make me feel insecure?" and "How do my emotions influence my interpretation of this?" When prompted to discuss how the student's own feelings of envy might impact her interpretation of this image, she concluded that her feelings of envy might have impacted her negative reaction to the image. Further prompts including "Do my own insecurities 
or feelings make me dislike or like this image? Do they make me have a desire to look like this? How does this affect my opinion of the person who created this image? What do I learn about myself from my reaction or interpretation?" resulted in the student concluding that her comparison of herself to the girl in the image not only drove her negative reaction to the image, but also elicited feelings of envy and personal body shame.

Following the initial example, two additional images chosen by the student Figures 2 and 3 were discussed in a self-directed way with the student following the same four-question prompt but without providing follow-up questions to determine if the student retained the analysis skills discussed in the first example. The student was able to identify two audiences (Question 1) without prompts on 2 of 2 opportunities, one or more messages (Question 2) without prompts on 2 of 2 opportunities, no personal feeling (Question 3) without prompts on 2 of 2 opportunities, and no interpretation (Question 4) based on the feelings identified in Question 3 without prompts on 2 of 2 opportunities. Without guidance or prompts, the student's reaction to each image was visibly negative and at times she even laughed at or mocked the image.

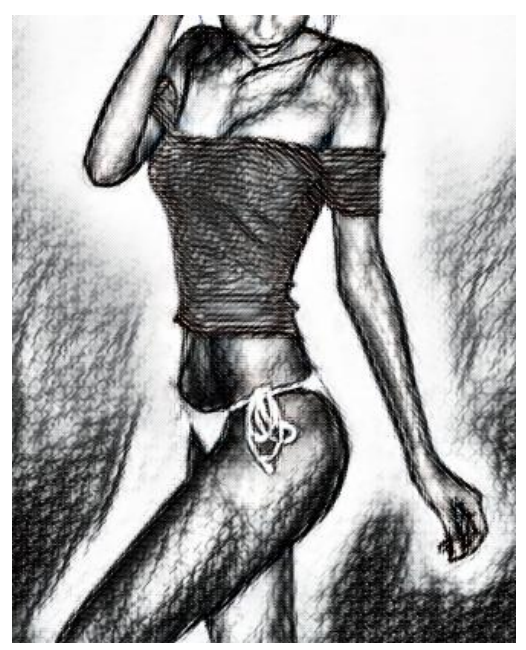

Figure 2. Selfie in bikini bottom and crop top. Ilustration adapted from Instagram.

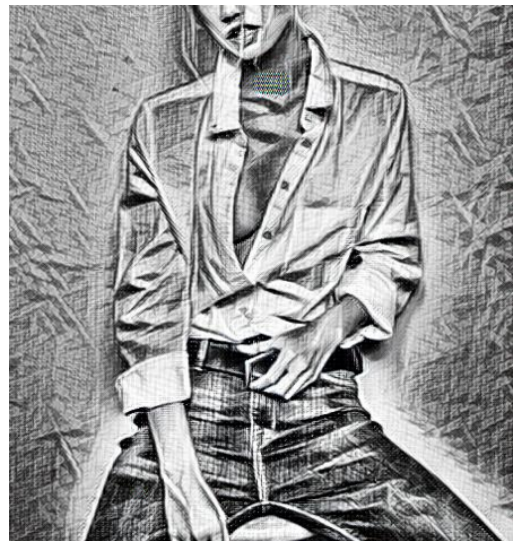

Figure 3. Selfie of woman in unbuttoned shirt. Illustration adapted from 
Instagram.

Based on the responses to the first image with guided discussion and prompts, it was clear the student was engaging in social comparison, which largely fueled the feelings of negativity towards the image (Fardouly et al., 2015; Hedley \& Young, 2006; Vogel et al., 2015). The student had difficulty identifying her feelings about each image, often using action phrases such as, "I want to roll my eyes," but could not effectively identify the specific emotion which led to this action.

Due to the student's lack of self-awareness, she had subsequent difficulty identifying her interpretation of the image, stating that the individuals in the image wanted to grab attention with their appearance. She also indicated some confusion between the image creator's intention and her own interpretation. These findings suggest some expected social and emotional learning deficits in students with autism spectrum disorders and emotional and behavioral disorder when analyzing media. This case study provides suggestive evidence of a promising opportunity to help students develop better social and emotional learning skills through social media literacy education. This case study demonstrates how selfawareness, perception, and perspective-taking are engaged when evaluating specific media like these provocative selfies posted on Instagram.

This framework and case study are only a brief sampling of the ways in which NAMLE's key questions can be applied in the special education setting to achieve social and emotional learning, and can be expanded in a number of ways for different types of media and social and emotional learning needs. Further analysis is required across many types of media for a variety of students with different socio-emotional needs to establish a clearer understanding of the benefits of media literacy as part of an individualized education plan intervention. While this framework is theoretical in nature, further research will determine the efficacy of the current model with the anticipation that adjustments be made based upon further research. Given the nature of the established frameworks for intervention provided by media literacy education and social and emotional learning, these limitations are not considered significant as this new framework provides an interdisciplinary extension of existing practices.

\section{Conclusion}

Special educators and media literacy professionals alike need to consider how all students create, consume, and analyze media, not just neurotypical students. By comparing the deficits in area of social and emotional learning for students with disabilities and the negative impact of media on these students, we can begin to understand how students with specific disabilities may be prone to the negative effects of media, even compounding an existing disability. Gaps in the areas of research and practice provide an opportunity for policy makers, practitioners, educators, and parents to create an interdisciplinary approach to social media literacy as social and emotional learning intervention for students with autism spectrum disorders and emotional and behavioral disorder. 


\section{Recommendations}

The following recommendations are provided based on existing research and practice in the fields of media literacy and disabilities.

- Research is needed to identify the impacts of media use students on autism spectrum disorders and emotional and behavioral disorder including to what extent media compounds or improves existing deficits such as impulse control, inattention, stress, anxiety, depression, empathy, and cyberbullying.

- Research is needed to establish the extent to which media literacy education impacts the outcomes for students with disabilities, if any differences exist in the efficacy of media literacy education for students with disabilities, and whether additional or alternative media literacy interventions are needed to address the specific learning needs of students with disabilities.

- Once further research and testing has been conducted, practitioners and educators would benefit from the creation of social media literacy curriculums and other interventions designed specifically for students with special needs.

- As research and practice for social media literacy as social and emotional learning intervention evolve, professional development opportunities should be designed for existing educators as well as those entering the field of special education.

\section{References}

Adams, D. (2013). The application of social-emotional learning principles to a special education environment. Korean Journal of Educational Policy, Special Issue. The Responsibility of the School for Promoting Students' Social-Emotional Character, and Moral Development and Preventing Bullying: Implications for Educational Policy, 103-118. Retrieved from https://www.kedi.re.kr/khome/main/journal/selectJournalForm.do?plNum $0=9533$

Baron-Cohen, S., \& Wheelwright, S. (2004). The empathy quotient: An investigation of adults with Asperger Syndrome or high functioning autism, and normal sex differences. Journal of Autism and Developmental Disorders, 34(2), 163-175.

Boyle, S. C., LaBrie, J. W., Froidevaux, N. M., \& Witkovic, Y. D. (2016). Different digital paths to the keg? How exposure to peers' alcohol-related social media content influences drinking among male and female first-year college students. Addictive Behaviors, 57, 21-29. doi:10.1016/j.addbeh.2016.01.011.

Brackett, M. A., \& Rivers, S. E. (2013). Transforming Students' Lives with Social and Emotional Learning. New Haven, CT: Yale Center for Emotional Intelligence. Retrieved from: http://ei.yale.edu/wpcontent/uploads/2013/09/Transforming-Students $\%$ E2\%80\%99-Liveswith-Social-and-Emotional-Learning.pdf.

CASEL(a) (2016). The Collaborative for Academic, Social, and Emotional Learning. Retrieved from: http://www.casel.org/core-competencies/ 
CASEL(b) (2016). SEL Outcomes. casel.org. Retrieved from: http://www.casel.org/impact/

Common Sense Media (2015). The Common Sense Consensus: Media Use by Tweens and Teens. commonsensemedia.org. San Francisco, CA: Common Sense Media Inc. Retrieved from: https://www.commonsensemedia.org/sites/default/files/uploads/research/c ensus executivesummary.pdf

den Hamer, A. H., \& Konijn.E. A., (2015). Adolescents' media exposure may nncrease their cyberbullying behavior: A longitudinal study. Journal of Adolescent Health, 56(2), 203-8. https://doi:10.1016/j.jadohealth.2014.09.016

Elias, M. J., Zins, J. E., Weissberg, R. P., Frey, K. S., Greenberg, M. T., Haynes, N. M, Kessler, R., Schwab-Stone, M.E. \& Shriver, T. P. (1997). Promoting Social and Emotional Learning: Guidelines for Educators. Alexandria, VA: Association for Supervision \& Curriculum Development (ASCD).

Fardouly, J., \& Vartanian, L. R. (2016). Social media and body image concerns: Current research and future directions. Current Opinion in Psychology, Social media and applications to health behavior, 9, 1-5. https://doi:10.1016/j.copsyc.2015.09.005.

Flanigan, A. E., \& Babchuk, W. A. (2015). Social media as academic quicksand: A phenomenological study of student experiences in and out of the classroom. Learning and Individual Differences, 44, 40-45. https://doi:10.1016/j.lindif.2015.11.003

Hedley, D., \& Young, R. (2006). Social comparison processes and depressive symptoms in children and adolescents with Asperger syndrome. Autism,10(2), 139-53. https://doi:10.1177/1362361306062020

Hollis, R. B., \& Was, C. A. (2016). Mind wandering, control failures, and social media distractions in online learning. Learning and Instruction, 42, 10412. https://doi:10.1016/j.learninstruc.2016.01.007

Howey, P. (2012, March 22). What You Need to Know About IDEA 2004: Present Levels of Functional Performance and Functional Goals in the IEP. Wrightslaw.com. Retrieved from: http://www.wrightslaw.com/howey/iep.functional.perf.htm

Hwang, H. S. (2015). Awareness of the others on Facebook: Empirical analysis of social presence. Journal of Internet Computing and Services, 16(4), 9399. https://doi:10.7472/jksii.2015.16.4.93

Kennedy, J., \& Lynch, H. (2016). A Shift from offline to online: Adolescence, the Internet and social participation. Journal of Occupational Science, 23(2), 156-67. https://doi:10.1080/14427591.2015.1117523

Koutamanis, M., Vossen, H. G. M., \& Valkenburg, P. M. (2015). Adolescents' comments in social media: Why do adolescents receive negative feedback and who is most at risk? Computers in Human Behavior. 53, 486-94. https://doi:10.1016/j.chb.2015.07.016

Kowalski, R. M., Morgan, C. A., Drake-Lavelle, K., \& Allison, B. (2016). Cyberbullying among college students with disabilities. Computers in 
Human Behavior, 57, 416-27. https://doi:10.1016/j.chb.2015.12.044

Leitner, Y. (2014). The co-occurrence of Autism and attention deficit hyperactivity disorder in children - What do we know? Frontiers in Human Neuroscience, 8, 1-8. https://doi:10.3389/fnhum.2014.00268

Li, W., Zhang, W., Xiao, L., \& Nie. J. (2016). The association of Internet addiction symptoms with impulsiveness, loneliness, novelty seeking and behavioral inhibition system among adults with attentiondeficit/hyperactivity disorder (ADHD). Psychiatry Research, 243, 357364. https://doi:10.1016/j.psychres.2016.02.020

Lim, M., \& Yang, Y. (2015). Effects of users' envy and shame on social comparison that occurs on social network services. Computers in Human Behavior, 51, 300-311. https://doi:10.1016/j.chb.2015.05.013

NAMLE. (2007). Core Principles of Media Literacy Education in the United States. Cherry Hill, NJ: National Association for Media Literacy Education (NAMLE), Retrieved from: https://namle.net/publications/coreprinciples

Odacı, H., \& Çelik, C. B.. (2016). Does Internet dependence affect young people's psycho-social status? Intrafamilial and social relations, impulse control, coping ability and body image. Computers in Human Behavior, 57, 343-347. https://doi:10.1016/j.chb.2015.12.057

Pittman, M., \& Reich, B. (2016). Social media and loneliness: Why an Instagram picture may be worth more than a thousand Twitter words. Computers in Human Behavior, 62, 155-67. https://doi:10.1016/j.chb.2016.03.084

Rogow, F., \& Scheibe, C. (2007). Key Questions to Ask when Analyzing Media Messages. Cherry Hill, NJ: National Association for Media Literacy Education, Retrieved from: https://drive.google.com/file/d/0B8j2T8jHrlgCZ2Zta2hvWkF0dG8/view

Salovey, P. \& Mayer, J. D. (1990). Emotional intelligence. Imagination, Cognition, and Personality, 9, 185-211. doi:0.2190/DUGG-P24E-52WK6CDG

Vogel, E. A., Rose, Okdie, B. M., Eckles, K., \& Franz, B. (2015). Who compares and despairs? The effect of social comparison orientation on social media use and its outcomes. Personality and Individual Differences, 86, 249256. https://doi:10.1016/j.paid.2015.06.026

Vossen, H. G. M., and Valkenburg, P. M. (2016). Do social media foster or curtail adolescents' empathy? A longitudinal study. Computers in Human Behavior, 63, 118-24. https://doi:10.1016/j.chb.2016.05.040

Woods, H. C., \& Scott, H.. (2016). \#Sleepyteens: Social media use in adolescence is associated with poor sleep quality, anxiety, depression and low selfesteem. Journal of Adolescence, 51, 41-49. https://doi:10.1016/j.adolescence.2016.05.008 